\title{
Sensors for physical fluxes at the sea surface: energy, heat, water,
}

\section{salt}

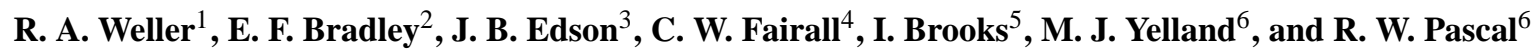 \\ ${ }^{1}$ Woods Hole Oceanographic Institution, Massachusetts, USA \\ ${ }^{2}$ CSIRO (Commonwealth Scientific and Industrial Research Organization) Land and Water, Canberra, Australia \\ ${ }^{3}$ University of Connecticut, Connecticut, USA \\ ${ }^{4}$ NOAA ESRL (National Oceanic and Atmospheric Administration, Earth System Research Laboratory), Boulder, Colorado, \\ USA \\ ${ }^{5}$ University of Leeds, Leeds, UK \\ ${ }^{6}$ National Oceanography Centre, Southampton, UK
}

Received: 9 June 2008 - Published in Ocean Sci. Discuss.: 11 July 2008

Revised: 17 November 2008 - Accepted: 17 November 2008 - Published: 10 December 2008

\begin{abstract}
The current status of meteorological sensors used aboard ships and buoys to measure the air-sea fluxes of momentum, heat, and freshwater is reviewed. Methods of flux measurement by the bulk aerodynamic, inertial dissipation and eddy-correlation methods are considered; and areas are identified where improvements are needed in measurement of the basic variables. In some cases, what is required is the transition from emergent to operational technology, in others new technologies are needed. Uncertainties in measured winds caused by flow distortion over the ship are discussed; and the possible role of computational fluid mechanics models to obtain corrections is considered. Basic studies are also needed on the influence of waves and rain on the fluxes. The issues involved in the specification of sea surface temperature are described, and the relative merits of the available sensors are discussed. The improved capability of buoy-mounted systems will depend on the emergence of low-power instruments, and/or new means of increasing the available power capacity. Other issues covered include the continuing uncertainty about the performance of rain gauges and short-wave radiometers. Also, the requirements for new instruments to extend the range of observations to extreme wind conditions are outlined, and the latest developments in the measurement of aerosol fluxes by eddy-correlation are presented.
\end{abstract}

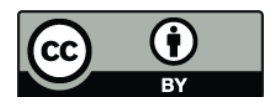

Correspondence to: R. A. Weller (rweller@whoi.edu)

\section{Introduction}

This paper is a report on the present status of sensors used on ships and buoys to observe the fluxes of energy, heat, water, and salt at the air-sea interface. For application in climate research, these fluxes are required at high accuracy and subdiurnal time resolution. For example, the sensitivity of model prediction to small changes in the fluxes is well-known (e.g. Miller et al., 1992). Recent research programs and long-term climate observing requirements have identified a target accuracy of $10 \mathrm{Wm}^{-2}$ over periods of weeks and longer; Weller and Taylor (1993) reviewed the nature of the oceanic surface fields and the background for this target. The implications for the required accuracy of specific sensors are discussed in subsequent sections and more fully in Table 1 of Bradley and Fairall (2007). The present paper indicates the challenges to be addressed and the potential areas of further development on sensors to meet these requirements. Because the quantification of the air-sea fluxes can be done by different methods (direct covariance, inertial dissipation, bulk aerodynamic), we summarize these methods in introducing the associated sensors. We focus here on momentum flux and freshwater flux, and on the heat flux with its four principal components; shortwave and longwave radiation, latent and sensible heat flux. Appendix A provides useful web links for those seeking further information.

Published by Copernicus Publications on behalf of the European Geosciences Union. 


\section{Momentum flux}

\subsection{Introduction}

Methods for estimating momentum flux depend either on sensors of the turbulence components of the wind or of the mean wind speed. The direct covariance flux (DC) method, summarized in Edson et al. (1998), uses frequentlysampled, direct observations of platform motion and threedimensional wind velocity in the frame of the platform to determine wind velocity fluctuations $\left(u^{\prime}, v^{\prime}\right.$, and $\left.w^{\prime}\right)$ and in turn compute the vector components of the wind stress, $\tau$ $\operatorname{sg}$ (vertical flux of horizontal momentum), $\rho<u^{\prime} w^{\prime}>$ and $\rho<v^{\prime} w^{\prime}>$ where $\rho$ is air density. The inertial dissipation (ID) method (Edson et al., 1991; Yelland et al.,1994) uses observations of turbulent wind fluctuations in a frequency range known as the inertial sub-range to compute power spectra and then infers the magnitude of the wind stress from spectral amplitudes. The bulk aerodynamic (BA) method (Large and Pond, 1981; Fairall et al., 1996b, 2003) uses observations of the mean wind, and a bulk formula of the form $\tau=\rho \mathrm{C}_{D}\left[U(z)-U_{0}\right]^{2}$, where $U(z)$ is the mean wind at height $z, U_{0}$ is the surface current, and $C_{D}$ is a drag coefficient which varies with height $\mathrm{z}$, and atmospheric stability. Various formulations for the drag coefficient have been determined using stress measurements using the DC (e.g. Smith, 1980; Fairall et al., 2003; Lange et al., 2004) and/or ID (Yelland et al., 1998, Drennan et al., 2005) methods. To compare observations taken at different heights and in different situations, it is usual to reference the measured drag coefficient to the "standard" height of $10 \mathrm{~m}$, and to adjust it to neutral atmospheric stability; this is normally designated $C_{D 10 n}$. The history of the development of drag coefficients from simple early forms to the advanced algorithms in current use can be found in WCRP (2000, Sect. 7) and Bradley and Fairall (2007, Sect. 11). The three momentum flux estimation methods are compared in Frederickson et al. (1997).

\subsection{Flow distortion}

A source of error, which affects all methods, is wind flow distortion. All platforms disturb the flow of air to the anemometer to some degree, introducing a bias to the mean wind speed and possibly distorting the turbulent eddies at some scales. The flow of air may also be displaced vertically as it flows over the platform. Computational fluid dynamics models have been used to simulate the mean flow around various research ships and to derive corrections for the mean wind speed measurements (Yelland et al., 1998; Yelland et al., 2002; Dupuis et al., 2003; Popinet et al., 2004; Moat et al., 2005). These models also provide an estimate of the vertical displacement of the flow, which is required for height adjustment of the BA measurements. It is also needed to correct the ID measurements of the wind stress (Yelland et al, 1998), which may be biased by $60 \%$ or more. The ID method ex- amines the turbulence at high frequencies, i.e. eddy scales which are small compared to the measurement height; Yelland et al. (2002) suggest that these eddies are not distorted by the platform. In contrast, measurements made using the DC method cannot be corrected directly since the numerical models cannot simulate the turbulent flow field itself. In this case the dominant scales are associated with the larger eddies which may be distorted by the presence of the platform. Comparison of DC with (corrected) ID results from the same instrument may show a systematic discrepancy, which could be attributed to the effect of flow distortion on the DC data. But it could also be due to the effect of waves on the different methods (e.g. Janssen, 1999; Taylor and Yelland, 2001), on the empirical coefficients used (e.g. Taylor and Yelland, 2000), or on a combination of these factors.

Particularly in the case of ships, the pattern of wind flow distortion depends on the angle of the platform to the wind. For the preferred situation with bow into wind, Moat et al. (2005) and Bradley and Fairall (2007) illustrate the best locations for anemometers to minimize the wind distortion error. It affects not only the stress measurements, but also those of the turbulent heat fluxes (described below). because one or more of the wind components enters the flux calculation whatever method (DC, ID or BA) is used,. Even for the bulk method, a 3-component sonic anemometer, which can measure tilt of the flow, is preferable to cup or propeller instruments. This makes it possible to estimate the small uncertainty in the scalar quantities due to vertical gradients. The effect of flow distortion on raingauges is discussed in Sect. 9.2. The only meteorological instruments unaffected by wind flow distortion are short- and long-wave radiometers.

\subsection{Instruments}

Sonic anemometers or fast response mechanical anemometers are used for turbulent velocity observations. Sonic anemometers and platform motion sensors are typically combined on moving platforms to estimate fluxes using the DC method. Fast response sensors are also required for the ID method but motion corrections are not needed. The inertial dissipation and bulk aerodynamic methods both require additional observations of temperature and water vapor concentration to determine the stability of the atmospheric surface layer. These measurements are used to determine the values of semi-empirical functions required by these methods and to adjust the value of the transfer coefficient required by the BA method. Because of the need for the stability adjustment, the platform being used for both ID and BA momentum flux estimation should also be equipped with the sensors needed to estimate air-sea heat flux. Similarly, if DC stress measurements are to be related to the wind speed to calculate a $10 \mathrm{~m}$ neutral drag coefficient then atmospheric stability again needs to be accounted for. A summary of micrometeorology sensors used to compute the momentum and heat fluxes is 
Table 1. Exemplary wind and momentum flux sensors.

\begin{tabular}{lllll}
\hline Variable/Sensor & Range & Accuracy/Uncertainty & Reference & Notes \\
\hline Wind & & & & \\
R. M. Young Model 5103 & $0-100 \mathrm{~m} \mathrm{~s}^{-1}$ & $+/-3 \mathrm{~m} \mathrm{~s}^{-1}$ or 1\% & www.youngusa.com & Propeller-vane \\
$\begin{array}{l}\text { Gill Windobserver II } \\
\text { Momentum }\end{array}$ & $0-65 \mathrm{~m} \mathrm{~s}^{-1}$ & $2 \%$ & www.gill.co.uk/ & 2-axis sonic, RS 422 output \\
Gill 3-Windmaster Pro & Wind speeds of $0-65 \mathrm{~m} \mathrm{~s}^{-1}$ & Not listed & www.gill.co.uk/ & 3-axis sonic \\
\hline
\end{tabular}

found in Edson (2001). Present thinking also suggests that if possible there should be coincident observation of surface waves, including directional characterization where possible.

Anemometers for the mean wind have typically been cup and vane or propeller-vane types, especially on buoys where power is limited. However, low-power sonic anemometers are in use on buoys and offer the advantage of having no moving parts. Icing is a challenge and requires heat elements to prevent ice accretion. Responsiveness in mechanical anemometers argues for low mass, but high winds and boarding waves can damage lightly built anemometers. Table 1 provides a summary and further information about typical, modern instruments used for measuring winds and estimating momentum flux. Figure 1 shows a surface buoy recently deployed in the core of the Gulf Stream. Three propeller-vane anemometers were mounted in an attempt to provide redundancy. Within the one-year deployment all three sensors were damaged, losing their propellers.

Except for sensor and sampling issues, the DC method is the most direct estimate of the true surface stress (which also applies to the heat fluxes). The other methods (ID or bulk) involve empirical coefficients and functions that can be tuned to match DC measurements on average but may give poor results in certain situations. For example, $C_{D}$, is usually represented as a simple function of wind speed but observations show that, at a given mean wind speed, the stress can be different for different surface wave conditions. Considerable effort has been expended to add wave parameters (e.g., wave age, wave height and/or period) to the parameterization of $C_{D}$ (see Drennan et al., 2005 for a review) but so far success has been modest. Waves may also affect bulk estimates of momentum by biasing the buoy measurement of mean wind speed either through sheltering in the trough (Large et al., 1995) or wave-induced buoy motions increasing the measured wind slightly (Taylor et al., 2001). The Large et al. (1995) study compared buoy winds with NWP winds and found that the buoys gave lower winds, particularly in storms. A recent study comparing buoy and ship winds (Thomas et al., 2005) found similar results. This is a tractable problem, but so far a simple solution has not been found. It is now clear that wave measurements should be made on buoys even if DC flux methods are used. However, appropriate instruments for this purpose are not readily available; microwave radar, li-

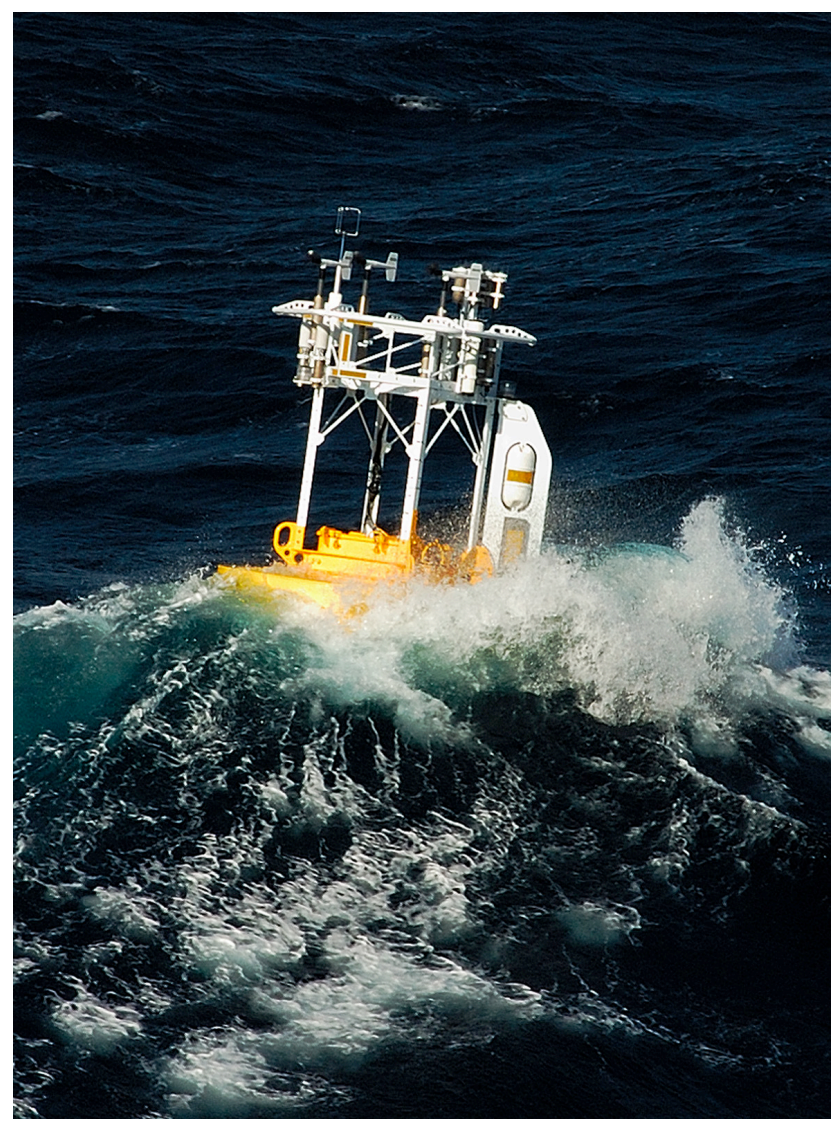

Fig. 1. Surface buoy deployed in 2005-2006 in the core of the Gulf Stream, equipped with three propeller-vane anemometers and a sonic anemometer for the DC method (S. Whelan, WHOI).

dar, and sonar transmitters have been used to observe wave characteristics, but none has emerged as a likely operational device for use on ships or buoys. For basic surface wave and well information gyroscopically stabilized platforms combined with accelerometers and magnetic compasses can be run for periods of time, but their power consumption prevents continuous sampling. More recent operational surface wave observing systems with lower power consumption use a combination of a magnetometer, angular rate gyros, and accelerometers. 


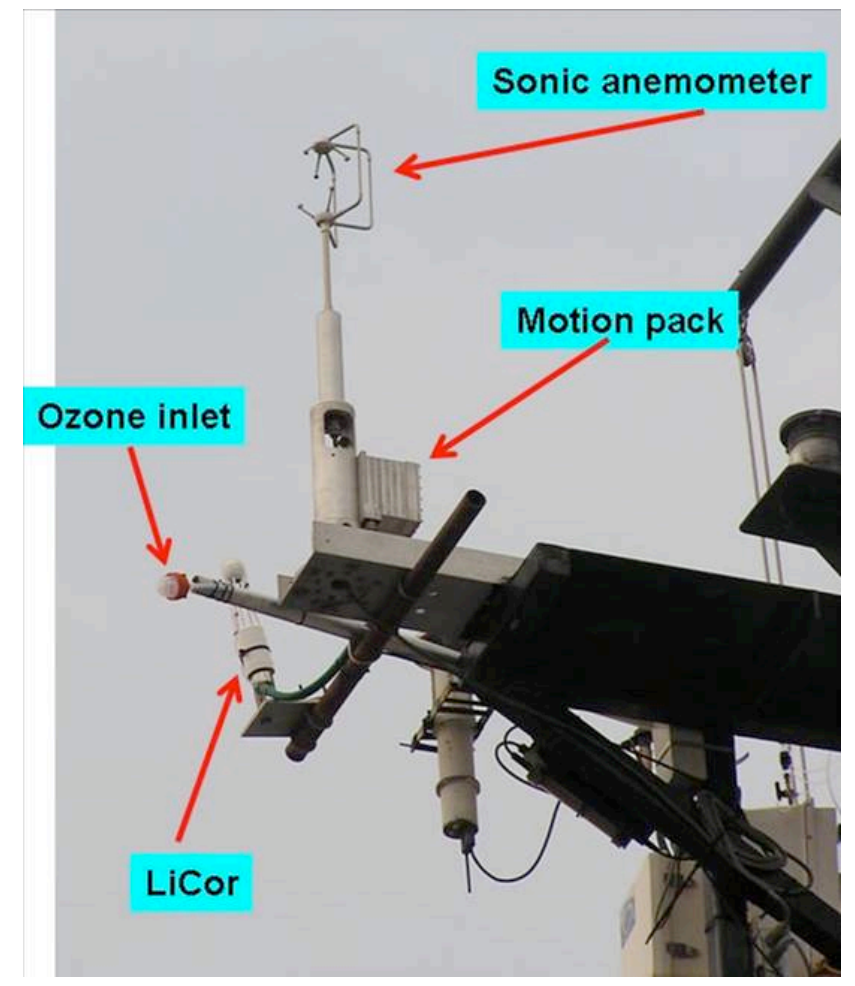

Fig. 2. High-speed flux sensors on the jackstaff of the NOAA Ship Ronald H. Brown. They consist of an infrared hygrometer (LICOR), ship-motion sensor package and sonic anemometer.

\section{Heat flux - latent}

As with momentum flux, there are approaches using mean sensors together with bulk formulae and also using fast response sensors. Inertial dissipation and DC methods for latent heat flux have been described by Edson et al. (1998) and Fairall and Larsen (1986). The challenge for the DC method is to obtain the specific humidity fluctuations, $q^{\prime}$, so that the latent heat flux, $\rho \mathrm{L}_{e}<\mathrm{w}^{\prime} \mathrm{q}$ ' $>$ can be estimated (here $L_{e}$ is the latent heat of evaporation). The ID method also requires rapid sampling of humidity to compute the required power spectrum. Typically, the fast response sensors used on ships and buoys use the absorption of specific frequencies in the infrared to monitor humidity fluctuations and other frequencies to check the cleanliness of lenses and/or mirrors. Simultaneously, a mean humidity sensor is used as a reference to check the calibration of the infrared hygrometer (Takahashi et al., 2005). A LI-COR 7500 infrared hygrometer is shown in Fig. 2 collocated with a 3-D sonic anemometer.

A reliable mean humidity sensor is needed for the bulk aerodynamic method, where the latent heat flux is given by $Q_{L}=L_{e} E=\rho C_{E}(z) L_{e} U(z)\left(Q(z)-Q_{0}\right)$, where $E$ is the moisture flux, $Q(z)$ is the specific humidity measured at height $\mathrm{z}, Q_{0}$ is the surface saturation specific humidity, and $C_{E}(z)$ is the transfer coefficient for moisture (known as the Dalton number) which, as for momentum, is height and sta-
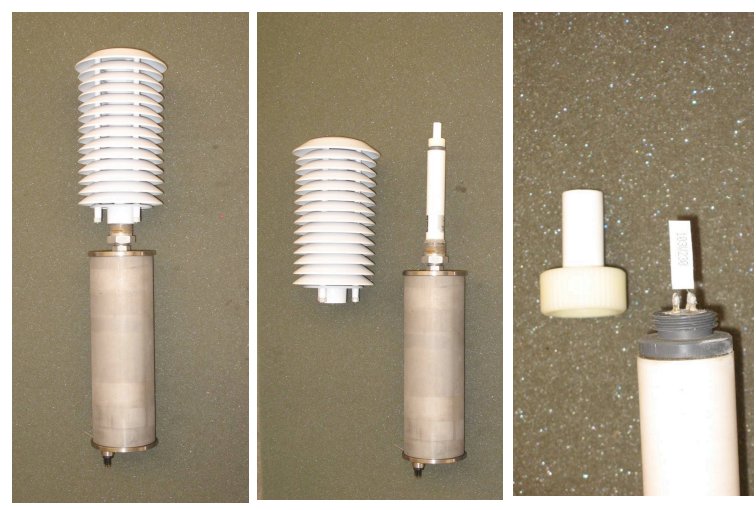

Fig. 3. (left) Relative humidity and air temperature unit mounted in Gill Multi-plate radiation shield; (center) With shield removed; (right) Close up of sensor and Teflon cover.

bility dependent. The bulk aerodynamic method requires an estimate of the sensible and latent heat fluxes for height and stability corrections. Bradley and Fairall (2007) provide a description of advanced bulk algorithms and values of thermodynamic parameters such as $L_{e}, \rho, \mathrm{C}_{p}$ (the specific heat of air at constant pressure) and relevant constants.

The challenges for mean humidity sensors are stability of calibration in the face of contaminants (sea spray, salt, organics from the sea surface, aerosols, stack gas on ships), linearity of calibration at high humidities (above 90\% RH), hysteresis at high humidity, and durability. While chilled mirror dew-point hygrometers and automated wet-and-dry bulb thermometers (psychrometers) have been used, current practice focuses on less complicated sensors, especially for buoys where power is at a premium. An example is the Vaisala HUMICAP, a thin film polymer sensor whose capacitance changes with relative humidity (RH). A platinum resistance thermometer is co-located with the humidity sensor, to measure air temperature and thus enable conversion from $\mathrm{RH}$ to other expressions of atmospheric humidity. The sensors are enclosed within a Gore-Tex or porous Teflon sleeve (Fig. 3), to keep water out and whose slippery surface prevents salt crystals (left behind from evaporating spray) from adhering and affecting the humidity measurement. The sensor element is mounted within a radiation shield to minimize error due to solar heating. On ships, the shield is usually aspirated with a fan, but on buoys where power is at a premium, naturally ventilated shields must be used (Richardson et al., 1999); the Gill multiplate shield shown in Fig. 3 is a passive radiation shield in common use. Such combined temperature/humidity sensors have been deployed successfully for a year at a time on buoys, providing accuracies of $\sim 3 \% R H$. 
Table 2. Radiation sensors.

\begin{tabular}{|c|c|c|c|c|}
\hline Variable/Sensor & Range & Accuracy/Uncertainty & Reference & Notes \\
\hline $\begin{array}{l}\text { Eppley Black and White } \\
\text { Pyranometer }\end{array}$ & $0-2800 \mathrm{~W} \mathrm{~m}^{-1}$ & $\begin{array}{l}1-3 \% \text { from } \\
\text { different sources }\end{array}$ & http://www.eppleylab.com/ & $\begin{array}{l}\text { Manufacturer does not } \\
\text { provide overall accuracy }\end{array}$ \\
\hline $\begin{array}{l}\text { Eppley Precison Spectral } \\
\text { Pyranometer }\end{array}$ & $0-2800 \mathrm{~W} \mathrm{~m}^{-1}$ & $\begin{array}{l}1-3 \% \text { from } \\
\text { different sources }\end{array}$ & http://www.eppleylab.com/ & $\begin{array}{l}\text { Manufacturer does not } \\
\text { provide overall accuracy; } \\
\text { consider more accurate } \\
\text { than black and white }\end{array}$ \\
\hline Kipp and Zonen CMP 22 & $0-4000 \mathrm{~W} \mathrm{~m}^{2}$ & $\begin{array}{l}.2 \text { to } .5 \% \text { from } \\
\text { different sources }\end{array}$ & http://www.kippzonen.com/ & $\begin{array}{l}\text { Manufacturer does not } \\
\text { provide overall accuracy; } \\
\text { identified as research quality }\end{array}$ \\
\hline \multicolumn{5}{|l|}{ Incoming Longwave } \\
\hline Kipp and Zonen CGR 4 & Not listed & $\sim 1 \%$ from several sources & http://www.kippzonen.com/ & Research grade \\
\hline
\end{tabular}

\section{Heat flux - sensible}

The present status of sensible heat flux measurements at sea is much the same as for latent heat flux, except that stable, accurate temperature sensors are more readily available and proven. Measurements of the fluctuating air temperature $T^{\prime}$ enables calculation of sensible heat flux $Q_{s}=\rho C_{p}<w^{\prime} T^{\prime}>$ by the DC and ID methods, or by the BA method as $\rho C_{P} C_{H}(z) U(z)\left(\theta(z)-T_{S}\right)$, where $C_{H}$ is the height and stability dependent heat transfer coefficient (or Stanton number), $\theta(\mathrm{z})$ is the potential temperature at height $z$, and $T_{S}$ is the sea surface temperature. The potential temperature accounts for the reduction of temperature due to the adiabatic lapse rate, $\gamma \cong-0.01\left({ }^{\circ} \mathrm{Cm}^{-1}\right)$, and can be obtained from the measurement of air temperature $T(z)$ using $\theta(z)=T(z)-\gamma z$.

Thermistors and platinum resistance thermometers (PRTs) are the most convenient sensors for air temperature measurement, using the BA method. At present there is a wide choice of both types of sensor which, when well calibrated, offer adequate accuracy and stability $\left(\sim 0.01^{\circ} \mathrm{C}\right)$, as well as reproducibility from the manufacturer. PRTs are often provided alongside the relative humidity sensor in commercial instruments. Thermocouples are no longer commonly used because of their low signal and sensitivity to the many sources of electromagnetic radiation found aboard ships. Air temperature sensors must be shielded from direct sunlight. As noted in the previous section, naturally ventilated radiation shields are typical on both ships and buoys, but aspirated shields are recommended when sufficient power is available. In low wind conditions Anderson and Baumgartner (1998) observed errors of up to $3^{\circ} \mathrm{C}$ using only the shields shown in Fig. 3. Shielding from rain, from salt spray (hygroscopic salts can attract moisture and then lead to cooling during subsequent evaporation), and from radiative heating errors (from sunlight, direct or reflected off the ship or buoy, or from heat released from the ship or buoy) is necessary to avoid introducing biases larger than the fundamental sensor accuracy.

DC estimates of sensible heat flux involve correlation of the motion-corrected values of vertical wind velocity with accurate measurement of the fluctuating air temperature. For the latter, fast response PRTs, thermistors, or thermocouples can be used (Edson, 2001). Over land, these probes are typically mounted on light, open frames to reduce the effect of solar heating, and directly exposed to the air. Unfortunately, this approach does not work well over the ocean, as it exposes the delicate probes to the harsh marine environment resulting in frequent damage. In addition, the exposed sensors become covered with salt from sea-spray, which causes spurious temperature fluctuations due to condensation and evaporation of water vapor on the salt particles (Schmitt et al, 1978). Attempts to shield these probes inevitably reduce their high frequency response thus limiting their suitability for the DC method.

Researchers have increasingly turned to sonic thermometry to resolve this problem. Sonic temperature is measured by sonic anemometers by computing the fluctuation in the speed of sound (C) using the relationship, $T_{\text {sonic }}=C^{2} / 403$, after correcting for velocity crosstalk (Schotanus et al., 1983; Larsen et al., 1993). Therefore, sonic thermometers share many of the positive attributes of sonic anemometers and are fairly insensitive to sea-salt contamination. It should be 
Table 3. Exemplary humidity, air temperature, sea temperature and latent and sensible heat flux sensors.

\begin{tabular}{|c|c|c|c|c|}
\hline Variable/Sensor & Range & Accuracy/Uncertainty & Reference & Notes \\
\hline \multicolumn{5}{|l|}{ Humidity } \\
\hline Vaisala Humicap & $0-100 \%$ & $+/-3 \% \mathrm{RH}$ & www.vaisala.com & Thin film polymer; mean \\
\hline Rotronic MP-101A & $0-100 \%$ & $+/-1.5 \% \mathrm{RH}$ & www.rotronic-usa.com & \\
\hline \multicolumn{5}{|l|}{ Air temperature } \\
\hline Thermistor & As needed & $0.005^{\circ} \mathrm{C}$ & www.ysi.com/ & $\begin{array}{l}0.1^{\circ} \mathrm{C} \text { in field, worse in } \\
\text { low wind if not ventilated }\end{array}$ \\
\hline \multicolumn{5}{|l|}{ Sea surface temperature } \\
\hline Thermistor & As needed & $0.005^{\circ} \mathrm{C}$ & www.ysi.com/ & $\begin{array}{l}0.1^{\circ} \mathrm{C} \text { in field; accuracy less } \\
\text { due to placement at depth below } \\
\text { surface, need to extrapolate to surface }\end{array}$ \\
\hline
\end{tabular}

noted, however, that the speed of sound and therefore sonic temperature is a function of both temperature and humidity. Fortunately, this is advantageous in many investigations because the sonic temperature closely approximates the virtual temperature of moist air, $T_{\text {sonic }} \cong T_{v}=\mathrm{T}(1+0.61 \mathrm{Q})$. Therefore, a sonic anemometer/thermometer can estimate closely the buoyancy flux, $Q_{B}=\rho C_{p}<w^{\prime} T_{v}^{\prime}>$, which is required to compute the stability corrections required for the ID and BA methods. The main drawback is that this flux must be combined with measurement of the latent heat flux to estimate the sensible heat flux separately.

\section{Sea surface temperature}

\subsection{Introduction}

Particularly because of its role in the BA method of calculating heat fluxes, the sea temperature is required with considerable accuracy. In addition, one must consider at what depth in the surface layer the temperature should be measured for use in the bulk formula. Excepting in conditions of strong winds (which cause vertical mixing) and of low solar radiation, the upper few meters of the ocean exhibits a vertical temperature gradient due to solar warming through the surface. Also, at the interface is a cool skin caused by outgoing thermal radiation and sensible and latent heat loss (Fairall et al., 1996a). This vertical temperature structure is illustrated by Donlon et al. (2002). From physical considerations we argue that the appropriate temperature for air-sea exchange is at the interface itself, above any diurnal warm layer and the cool skin.

\subsection{Instruments}

This interface skin temperature cannot be measured with present technology, but measurement by infrared and microwave radiometers, such as those carried by spacecraft and a few instruments specially developed for use aboard ships, come close. These measure at depths from microns to a few mm depending on wavelength. Results from a cruise designed to compare measurements from seven such radiometers are given by Barton et al. (2004) and indicate that the target accuracy of $0.1 \mathrm{~K}$ is achievable. These instruments are not generally available, although one of them, based on a commercial pyrometer (Heitronics KT15), is under development as an affordable turnkey IR system. One difficulty is that the sky temperature is needed at the same time as the sea temperature to enable correction for a reflected component at the surface.

Until such an alternative becomes available, most water temperature measurements from aboard ships and buoys will continue to be made at various depths with instruments using PRTs or high quality thermistors as the sensor. The most common shipboard measurement of sea temperature comes from the ship's thermosalinograph. This instrument takes water in through a port at some depth (e.g. 3-7 m) down the hull. Properly calibrated, the basic accuracy of the instrument itself is of order $0.001{ }^{\circ} \mathrm{C}$, but several factors may degrade the measurement. A short run of pipe (ideally thermally insulated) and adequate flow rate are required to avoid temperature changes between port and sensor. If the port is some distance aft, because of the pattern of flow along the hull the water sample has likely originated from some other depth ahead of the ship. A better arrangement is when the thermosalinograph has its own intake port and pump near the bow of the ship, although there is still some uncertainty about the effective depth of measurement when the ship pitches in heavy seas and it may be necessary to devise means to cope with ingestion of air and bubbles.

Hull contact sensors for sea temperature are usually attached inside the bow of the ship below the water line. They are therefore easily accessible and avoid problems of exposure to the elements, but what they measure, and the effective depth, is uncertain. It is presumably some average of the surface water in contact with the hull, but because of the inherent uncertainty these sensors cannot be seriously considered for climate quality flux observations. 
Table 4. Exemplary rain and freshwater flux sensors.

\begin{tabular}{|c|c|c|c|c|}
\hline Variable/Sensor & Range & Accuracy/uncertainty & Reference & Notes \\
\hline \multicolumn{5}{|l|}{ Rain } \\
\hline R. M. Young 50202 & 0 to $50 \mathrm{~mm}$ column & $\sim 20 \%$ & www.youngusa.com/ & $\begin{array}{l}\text { Self-siphoning; wind can } \\
\text { blow rain over top }\end{array}$ \\
\hline Eigenbrodt SRM 450 & & Improved over RM Young & www.groddeck-defense.de/devices/srm450.htm & $\begin{array}{l}\text { Hasse gauge, disdrometer, } \\
\text { funnel and side catchment }\end{array}$ \\
\hline Optical Scientific ORG-815 & 0.1 to $500 \mathrm{~mm} \mathrm{hr}^{-1}$ & $5 \%$ of accumulation & www.opticalscientific.com & Optical scintillation \\
\hline
\end{tabular}

Some researchers measure sea temperature close to the surface by trailing a sensor (usually a thermistor) mounted at the end of a length of plastic hose as described by Fairall et al. (1997), or a rope with an internal conductor. It is towed from a light boom near the bow of the ship and extends as far out as practicable, preferably outside the bow wave. Underway in slight seas, the hose will follow the surface at a depth of $5-10 \mathrm{~cm}$, but in heavier seas will often become airborne. Comparisons with ships' thermosalinographs at night, and when the surface layer is well mixed to a considerable depth, indicates that the system is capable of $0.1{ }^{\circ} \mathrm{C}$ accuracy. During the day it captures nearly all the daytime surface warming, but is below the cool skin regime. In persistent stormy conditions it may have to be brought inboard to prevent its destruction. From buoys, a near-surface water measurement is often made from a fixed bridle. However, it has been found that, as in the case of the ship, flow distortion around the hull makes the depth of the measurement uncertain. A recent redesign of the system has the sensor attached to the upwind side of the buoy hull but free to move vertically and float at the surface.

Since diurnal warming can commonly exceed $3^{\circ} \mathrm{C}$, especially in the tropics, and a typical cool skin temperature depression is $0.3^{\circ} \mathrm{C}$, using the raw, uncorrected temperature measurement for $T_{s}$ in the bulk equation can lead to significant errors in the flux calculation. Advanced bulk algorithms include models for both the diurnal warming and cool skin, so that the interface temperature can be extrapolated from the measurement at known depth. This implies that, for bestquality flux estimates by the BA method, the sea temperature measurement must be accompanied by the depth of the sensor.

\section{Rainfall effects}

Because raindrops have considerable inertia they hit the sea surface with some residual horizontal velocity - this adds to the turbulent momentum flux. Fairall et al. (1996b) propose that the rain-driven component of the momentum flux can be represented as a fraction of the turbulent part, $\tau_{\text {Rain }} / \tau=0.18 R / U(10)$, where $R$ is the rain rate in $\mathrm{mm} / \mathrm{h}$. Thus, in a heavy rainstorm $(R=100 \mathrm{~mm} / \mathrm{h}$ at $U(10)=10 \mathrm{~m} / \mathrm{s}$ say) the momentum transferred to the ocean directly from the rain exceeds that due to wind stress. However, the situation is extremely complicated with both rain and wind influencing the wave field, which in turn affects surface roughness and the wind structure (Soloviev and Lukas, 2006, Chapter 2).

Similarly, the net air-sea heat flux includes a component of sensible heat from rainfall, which can be calculated from the rain rate and the temperature of raindrops, usually assumed to be close to the wet-bulb temperature at sea level (Gosnell et al., 1995). In the case of tropical deep convection it has been found that raindrops are about $0.2^{\circ} \mathrm{C}$ cooler than this temperature. Over extended periods, the contribution is small, but during heavy storms it can be several hundred $\mathrm{Wm}^{-2}$ and a significant component of a daily average net heat flux. To investigate further either of these air-sea exchange problems, precipitation sensors which measure the rain rate directly have a distinct advantage over volumetric instruments, as described below (Sect. 9).

\section{$7 \quad$ Extreme winds}

\subsection{Introduction}

The direct measurement of momentum, heat and mass exchange near the air-sea interface in extreme wind conditions remains one of the greatest observational challenges to marine research. The lack of data at wind speeds above $25 \mathrm{~m} / \mathrm{s}$ is a major impediment to forecasting storm intensity accurately. For example, numerical modelers have shown that extrapolation of current bulk parameterizations does not explain tropical cyclone and hurricane formation due to too much drag and/or too little heat exchange between the ocean and atmosphere (Emanuel, 1995). Our inability to make measurements at high wind speeds is due to sensor limitations under these harsh conditions, to platform motion and flow distortion by the platform, and to concerns for the safety of the vessels and those aboard. Therefore, it is unlikely that our understanding of air-sea exchange at very high wind speeds greater than, say, $25 \mathrm{~m} / \mathrm{s}$ can be significantly improved from ship-based measurements. High sea states and surface winds, low visibility and corrosive sea spray often make aircraft operations near the sea surface too dangerous to conduct during intense storms. 


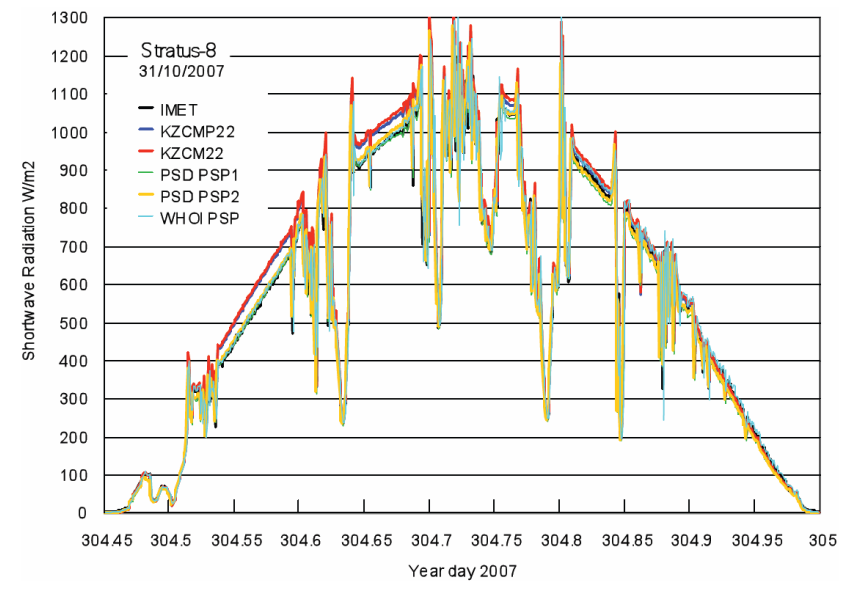

Fig. 4. A comparison of six shortwave radiometers, four Eppley PSP sensors (IMET, PSD PSP1, PSD PSP2, and WHOI PSP) and two from Kipp \& Zonen (KZCM22 and KZCMP22). Note the differences between the Kipp \& Zonen and Eppley sensors in clear sky conditions, which probably reflect both leveling inconsistencies and different calibration procedures.

\subsection{Platforms and instruments}

One solution is to make long-term, continuous, direct measurements of momentum, heat, and mass fluxes on coastal towers and on large oceanic moorings arranged along probable storm tracks. Another solution is to develop mobile systems that can be deployed in advance at predicted locations for tropical storm or hurricane landfall. However, these solutions do not solve the problem of having sensors capable of surviving extreme wind and sea conditions. For example, although more rigorous testing is required, the latest generation of sonic anemometers appears capable of providing accurate estimates of momentum and buoyancy flux to wind speeds approaching $30 \mathrm{~m} / \mathrm{s}$ in moderate precipitation; i.e., they can provide information in severe storms. Therefore, rugged, fast-response anemometers must be developed to survive extreme wind conditions encountered in hurricanes and typhoons.

Pressure anemometers (e.g., Brown et al., 1983; Oost et al., 1991; Rediniotis and Kisner, 1998) are a promising solution to the measurement of momentum fluxes under these conditions. Pressure-sphere anemometers are routinely used on research aircraft to obtain horizontal and vertical velocity fluctuations from the measured pressure fluctuations. Therefore, they are inherently designed to measure fluxes at the high relative velocities and thus at wind speeds found in hurricane conditions. Thanks to micro-processor based data loggers, the non-linear response of sensors such as pressure anemometers and thermistors is no limitation even in fast-response applications. The main challenge is to design an omnidirectional probe that can continue to make measurements in heavy rain and spray conditions. Eckman

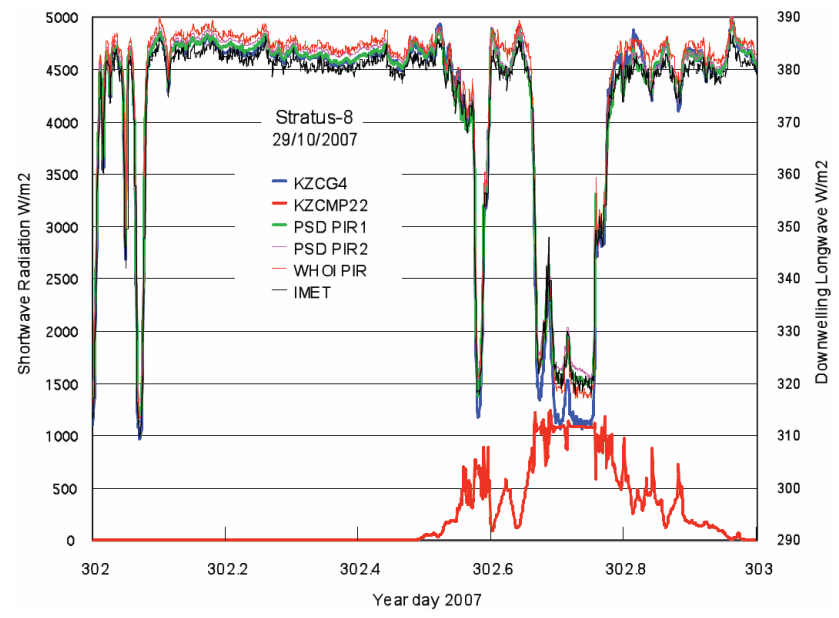

Fig. 5. A comparison of 5 longwave radiometers, four from Eppley and a KZCG4 from Kipp\&Zonen. The KZCMP22 pyranometer illustrates the daylight period.

et al. (2007) describe an omnidirectional pressure-sphere anemometer based on the BAT probe (Crawford and Dobosy, 1992) that overcomes rain contamination using a passive approach that uses gravity to keeps its pressure ports clear. Although Eckman et al. (2007) admit that a more active approach may be required in heavy rain, the device looks very promising for momentum exchange in extreme wind conditions.

The same cannot be said for latent and sensible heat flux measurements in these conditions. Rugged hygrometers and thermometers must be developed to handle the high winds and spray. At the moment, several of the sensors described above are being using with flow-through systems where large volumes of air are pumped past the probe. A small amount of air is then subsampled from this flow past the sensor to avoid contamination by rain and spray. However, there are a number of drawbacks to this approach (e.g., lags and loss of signal) and innovative solutions to this problem are still required.

\section{Heat flux - radiation}

\subsection{Introduction.}

Generally speaking, the radiative components are the largest in the air-sea heat budget. Under clear skies in mid-latitudes the downwelling solar or short-wave radiation (SW; wavelengths $0.1-4 \mu \mathrm{m}$ ) peaks well above $1000 \mathrm{Wm}^{-2}$ and even under cloudy skies the diffuse $\mathrm{SW}$ is often several hundred $\mathrm{Wm}^{-2}$, as illustrated in Fig. 4. Outgoing short-wave (the albedo; Payne, 1972) is only about $5 \%$ of this so the net effect is substantial heating of the ocean. Solar radiation is absorbed within the surface layer to a depth depending on the spectra of the incident radiation and on the water's optical 
absorption and scattering properties, which are wavelength dependent; the decay is often parameterized as the sum of two or more exponential terms (Ohlman et al., 2000; Ohlman and Siegel, 2000). More sophisticated spectrally dependent models capture the decay more accurately. In very clear water a few $\%$ can be found at $50 \mathrm{~m}$ depth.

Downwelling thermal or long-wave radiation (LW; wavelengths $4-100 \mu \mathrm{m}$ ) is emitted from atmospheric constituents, particularly water vapor, aerosols and clouds. It is absorbed within about $1 \mathrm{~mm}$ of the surface. Figure 5 shows a time series of LW radiation from the east Pacific under predominantly stratus cloud which cleared for a short period. Measurement of downwelling longwave radiation at sea was a challenge but is now more common and made to accuracies of $6 \mathrm{~W} \mathrm{~m}^{-2}$ (Dickey et al., 1994). Unlike over land, measurement of outgoing radiation $\left(\mathrm{SW}_{\uparrow}\right.$ or $\mathrm{LW}_{\uparrow}$ ) using a downward facing radiometer is not feasible routinely from ships or moorings because of the proximity of either platform. Outgoing long-wave is determined from the sea surface temperature $T_{S}(\mathrm{~K})$, via $\mathrm{LW}_{\uparrow}=\varepsilon \sigma T_{S}^{4}+(1-\varepsilon) \mathrm{LW}$, with $\varepsilon$ the emissivity of the sea surface (0.97) and $\sigma$ the Stefan-Boltzmann constant $\left(5.67 \times 10^{-8} \mathrm{Wm}^{-2} \mathrm{~K}^{-4}\right)$. The second term is the fraction of the downwelling $\mathrm{LW}$ reflected from the surface. For the case in Fig. 5, sea temperature was about $15.8^{\circ} \mathrm{C}$ and unaffected by the sky clearing; i.e. $\mathrm{LW}_{\uparrow}$ was $395.3 \mathrm{Wm}^{-2}$. So the net LW is the difference between two fairly large numbers; for most of the night it was a loss to the ocean of $10 \mathrm{Wm}^{-2}$ but this increased sharply to $75 \mathrm{Wm}^{-2}$ when the sky cleared.

\subsection{Instruments}

The instruments most commonly used for field measurement of downwelling SW (the pyranometer) and LW (the pyrgeometer) barely changed for half a century. Since, from the early 1990s, under the stimulus of climate research and developments in other flux instrumentation, the performance of these radiometers has been under close scrutiny, and several manufacturers have strived to make improvements. Not the least of these incentives has been the role of radiometers at sea and the target of $10 \mathrm{Wm}^{-2}$ (see Sect. 1) for accuracy in determining net air-sea heat transfer. There are several grades of both instruments - we consider only those that conform to the WMO criteria for a "first class" or research grade instrument.

SW and LW radiometers are physically similar (Fig. 6), both being broadband sensors which accept radiation from the skyward hemisphere through a transparent dome, impinging on the blackened surface of a thermopile. Typically, the thermopile sensitivity is less than $10 \mu \mathrm{V}$ per $\mathrm{Wm}^{-2}$ of radiation so amplification of a low-level signal is usually required. The instruments differ in the technical measures needed to account for the differing characteristics of solar and thermal radiation. The pyranometer uses a pair of concentric visually clear glass domes with spectral transmissivity between 0.3

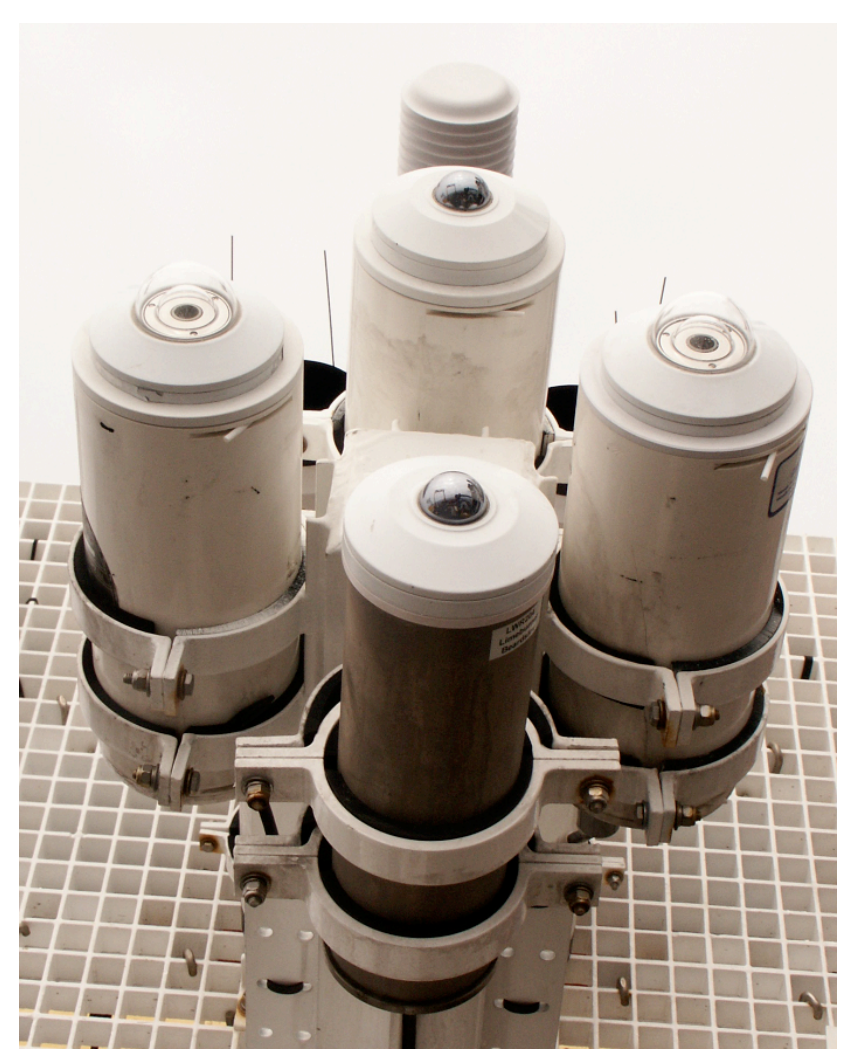

Fig. 6. A buoy radiometer assembly. For redundancy there are two Eppley PIRs (reflective domes) and two PSPs (clear domes) mounted on a buoy tower on top of tubes housing the associated amplifiers and electronics for conversion of the thermopile voltage to a calibrated, digital signal. In the background is a Gill multiplate radiation shield housing an air temperature/humidity sensor. (R. Weller, WHOI).

and $2.8 \mu \mathrm{m}$, and optimized for cosine response of the direct solar beam. It is so far unclear how serious an error is caused by tilting and rocking of the platform. The use of gimbaled mounts is dubious because of phase lag due to the response time of the radiometer, but recent trials of a dynamic leveling system were encouraging (Pezoa and Fairall, personal communication). The diffuse component of SW (mostly from clouds) is globally distributed. Maintaining cleanliness of the domes is a concern, especially since birds are attracted to this fishing perch, and vertical wires are often used to discourage them from landing. Other contaminants are dust, organic matter from the sea surface, and salt left behind by evaporation. It is good practice to return radiometers for post-deployment calibration before cleaning. 
Table 5. Ancillary sensors, accessories.

\begin{tabular}{|c|c|c|c|c|}
\hline Variable/Sensor & Range & Accuracy & Reference & Notes \\
\hline \multicolumn{5}{|l|}{ Barometric Pressure } \\
\hline Heise DXD & $\begin{array}{l}\text { Various, e.g } \\
0-150 \text { psi }\end{array}$ & $+/-.02 \% \mathrm{FS}$ & http://www.heise.com/products.cfm?doc_id=42 & $\begin{array}{l}\text { RS-232 or } \\
\text { RS } 485 \text { output }\end{array}$ \\
\hline \multicolumn{5}{|l|}{ Radiative sheilding } \\
\hline Eppley Ventilator & & & www.eppleylab.com/ & $\begin{array}{l}\text { Aspirator for } \\
\text { radiometers }\end{array}$ \\
\hline $\begin{array}{l}\text { RM Young } 41003 \text { Muliti- } \\
\text { Plate Radiation Shield }\end{array}$ & & & http://www.youngusa.com/ & $\begin{array}{l}\text { Gill multiplate } \\
\text { shield - passive }\end{array}$ \\
\hline $\begin{array}{l}\text { RM Young } 43502 \text { Aspirated } \\
\text { Radiation Shield }\end{array}$ & & & http://www.youngusa.com/ & $\begin{array}{l}\text { Electric fan, } \\
\text { active aspiration }\end{array}$ \\
\hline
\end{tabular}

Calibration of field pyranometers formerly used the sun as a source with reference to a standard pyrheliometer. Nowadays, presumably to avoid cloudy conditions, it is frequently performed indoors side-by-side with a similar reference pyranometer using a standard gas discharge lamp. The reference instrument itself is traceable to the World Radiometric Reference (WRR) held in Davos, Switzerland. Included in the calibration procedures are checks on cosine response, temperature dependence of the sensitivity, and dark offset. In high grade instruments these seem to make a small contribution to the calibration error. Recent optional improvements to performance are an embedded thermistor to apply the temperature correction, a quartz dome to extend the spectral range, and a ventilator (with heating) to prevent the cooling of the dome under clear skies and the consequent formation of dew or ice.

These improvements may prove marginal compared with calibration uncertainties. Figure 4 is from a shipboard test of instruments from two manufacturers, whose calibration references were presumably both traceable to the WRR. Yet during clear-sky periods the two types group separately, by $40-60 \mathrm{Wm}^{-2}$ in the morning; rather less but in the same sense in the afternoon. The diurnal change in this difference may be due partly to the difficulty referred to above, of leveling instruments aboard ship, but in the context of our $10 \mathrm{Wm}^{-2}$ goal such a systematic discrepancy is unacceptable. An early description of the WRR (Frohlich, 1991) noted that it "guarantees the worldwide homogeneity of radiation measurements within $0.1 \%$ precision", a prediction which seems to be "more honour'd in the breach than the observance" (Shakespeare, 1603).

The pyrgeometer uses a single silicon dome to admit infrared radiation, with a filter deposited on the inside to exclude solar radiation. This combination has spectral transmittance between about 4 and $50 \mu \mathrm{m}$. However, the thermopile thermal balance has three components; the LW from the sky, and thermal radiation from the body of the instrument and from its dome. Thermistors are embedded to monitor the body and dome temperatures, and the three signals are combined in the pyrgeometer equation (Fairall et al., 1998) to obtain the required downwelling LW. Since the sky component of LW is global, the dome does not need cosine response so Kipp and Zonen have recently introduced a much flatter "dome" which has better thermal bonding to the body. With body and dome at the same temperature the pyrgeometer equation is simplified.

Figure 5 is a comparison of four pyrgeometers from Eppley and one from Kipp and Zonen. Under cloudy conditions all pyrgeometers agree within $5 \mathrm{Wm}^{-2}$, a quite remarkable result, testament to the intense efforts by sea-going scientists over the past 15 years to understand and improve these instruments (Fairall et al., 1998; Payne and Anderson, 1999; Ji and Tsay, 2000; Pascal and Josey, 2000). The downward spikes of about $70 \mathrm{Wm}^{-2}$ signal a clear patch of sky above the ship. It is interesting to note that, during the lengthy clear period around midday, the small $\left(\sim 3 \mathrm{Wm}^{-2}\right)$ systematic night-time difference between the Eppley and Kipp and Zonen instruments increases to around $8 \mathrm{Wm}^{-2}$. This may signify shortwave leakage through the dome or inaccurate characterization of the dome heating effect. Pascal and Josey (2000) describe a method to calibrate for shortwave leakage resulting from a non-perfect SW filter applied to the dome. Other calibration factors are the sensitivity constant, $h$, which determines the scaling factor for the response of the sensor thermopile, and the dome body temperature coefficient, $k$, which compensates for the dome temperature being higher than the body temperature caused by solar heating of the dome. Shortwave leakage and the coefficient $k$ should be zero at night. Examining night-time data from a range of LW values allows the fundamental sensitivities of a number of pyrgeometers to be examined. Residual biases in daytime data during high levels of SW can then be attributed to imperfect calibration of the coefficient $k$ and the SW leakage. Solar heating of the dome and SW leakage both tend to increase the measured downwelling LW. If no sensitivity errors were found in the night-time data then this would suggest that sensor KZCG4 (Fig. 5) suffers least from the effects of dome heating and SW leakage. 


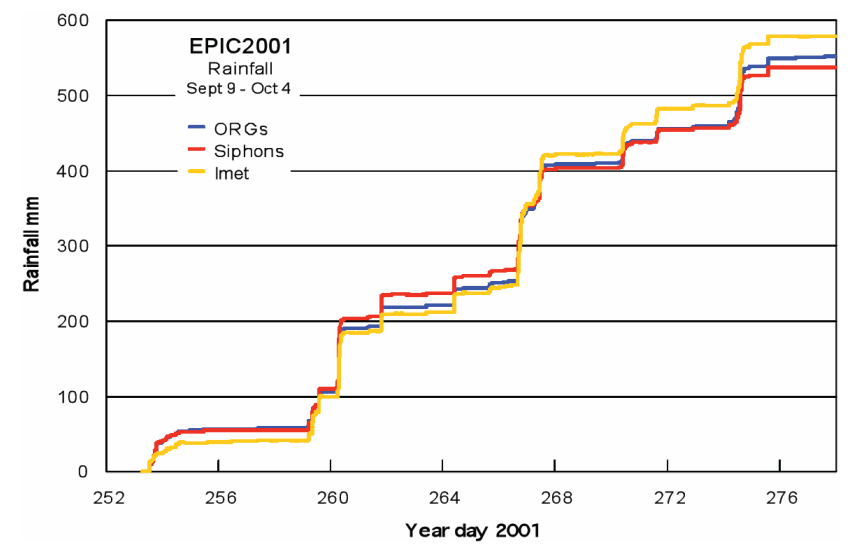

Fig. 7. Time series of rainfall measured on the NOAA Ship Ronald H. Brown in the eastern Pacific from 9 siphon and 3 optical rain gauges distributed around the ship. The data were analysed separately by sensor type and wind-speed corrections have been applied; Imet was a siphon gauge high on the foremast.

Calibration of infrared instruments is usually performed in a black body cavity either by the manufacturers themselves, or sent to a certified calibration laboratory. However, the Kipp and Zonen pyrgeometers used in this comparison were calibrated side-by-side against a secondary standard outside on a clear night. What uncertainties these different procedures may involve is not clear. However, proper calibration procedures and traceability are key to the reliability of field measurement.

\section{Freshwater flux}

\subsection{Introduction}

The global distribution of precipitation is at the heart of the earth's hydrological cycle and critical for our understanding and modeling of climate processes. Over land, precipitation is sampled by extensive networks of carefully installed and well-tended raingauges. But over $70 \%$ of the globe (the oceans) sampling of rainfall is sparse and difficult. This motivated the development of satellite-borne precipitation sensors, such as the Tropical Rainfall Measurement Mission (TRMM), still operational since its launch in 1997, and the cluster of satellites for the Global Precipitation Mission (GPM), due for launch in 2013. TRMM is limited to latitudes $\pm 38^{\circ}$ and revisit frequency is once or twice a day. The uncertainties involved in creating maps from such sparse information are clearly considerable, but the increased coverage of GPM will improve this. Rainfall is the most inhomogeneous of the meteorological variables, both as regards its location and intensity (see Fig. 7), so one important application for in situ measurements of rainfall is the validation of satellite products.

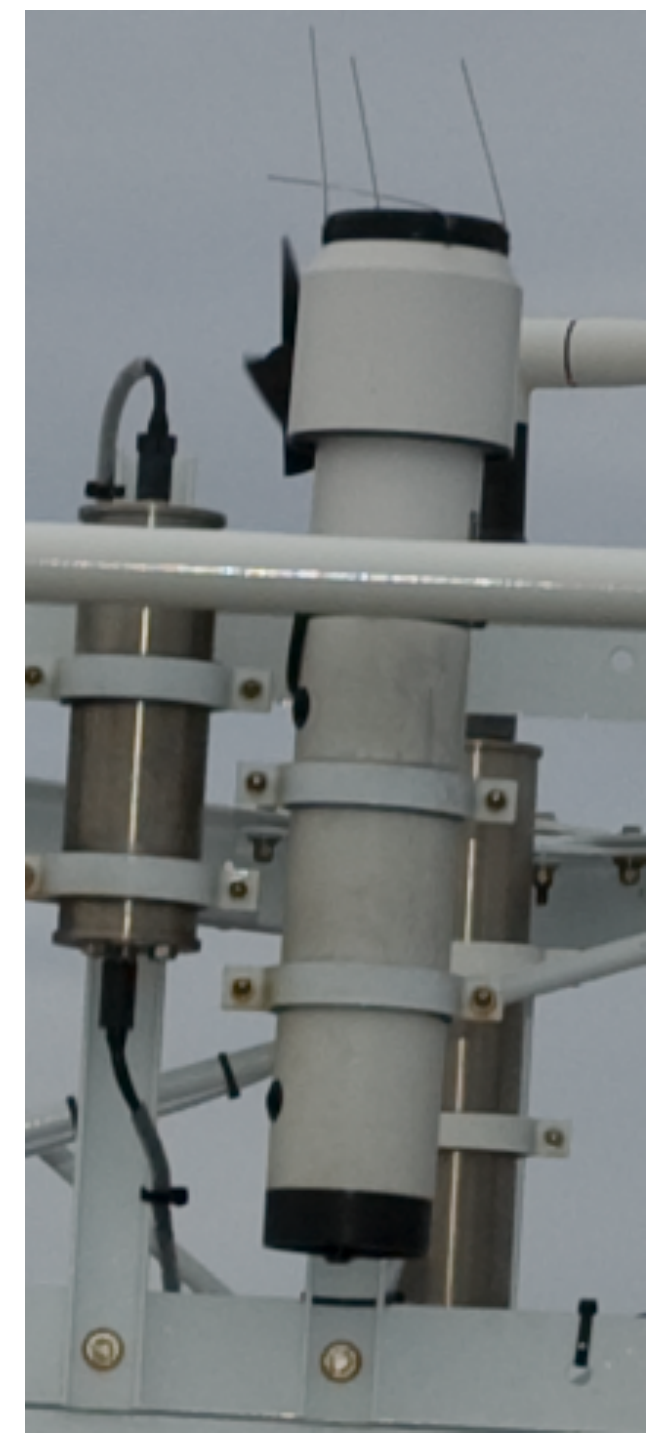

Fig. 8. RM Young 50202 self-siphoning rain gauge and associated electronics fitted to buoy tower.

On regional scales, a knowledge of net freshwater input to the ocean (Precipitation - Evaporation; $P-E$ ) is crucial in determining the thermodynamic stability and depth of the surface mixed layer, vertical and horizontal density gradients, and ocean budgets of heat and freshwater. Evaporation, $E$, can be calculated from latent heat flux. This evaporation not only cools the sea surface but also leaves salt behind as a mass flux. All models involving the coupled air-sea system would benefit from an increased sampling density and improved accuracy of precipitation measurements from ships and moorings

\subsection{Instruments}

The most common instrument for measuring rainfall at sea is the ubiquitous funnel gauge (Fig. 8). Because a tipping bucket won't work on an unsteady platform, sea-going 
gauges employ a self-siphoning system. The rainfall is recorded as it fills a reservoir which, at a certain point (usually equivalent to $50 \mathrm{~mm}$ of rain), empties and begins to refill. Rain falling during the siphoning process is not counted, and in a heavy rainstorm this loss can be significant. Also, in heavy seas the reservoir can empty prematurely. However, the most serious error arises from wind flow distortion by the ship causing raindrops to be blown over and around the funnel instead of falling in. The loss of catch is a function of relative wind speed and direction, and while typically $2-5 \%$ in land installations, can be $20-100 \%$ on a ship. The effect depends strongly on the location of the gauge.

Schemes involving an empirically determined dependence on relative wind speed have been used to estimate the loss, with limited success. Hasse et al. (1998) have developed a design of funnel gauge, attempting to overcome the wind loss using a different funnel shape, and by catching horizontally blown rain using flutes around the body of the instrument. The rain rates from the two sources are recorded independently, and combined using empirical wind-speed dependent weighting functions. This instrument must still be regarded as in the process of development.

Optical raingauges (ORGs) detect raindrops falling through a light-beam, either by the blockage produced or by using laser light which creates scintillation from the droplets. ORGs have several advantages; no mechanical parts, wide dynamic range from light drizzle to intense tropical rain, and the direct measurement of rainrate. Rainrate is the quantity needed to calculate the fluxes of heat and momentum associated with rain hitting the sea surface, and obviously depends on the time interval over which it is observed. ORGs have a built-in time constant of about $20 \mathrm{~s}$. The highest instantaneous rain rate ever noted by these authors is $220 \mathrm{mmhr}^{-1}$. The time series in Fig. 7 is based on 5-minute averages, the highest 5-min rainrate observed being $136 \mathrm{mmhr}^{-1}$ during the storm on day 260. This produced $670 \mathrm{Wm}^{-2}$ of heat flux and $0.202 \mathrm{Nm}^{-2}$ of momentum flux, compared with $240 \mathrm{Wm}^{-2}$ of latent plus sensible heat flux and $0.085 \mathrm{Nm}^{-2}$ of wind stress. Rainfall accumulation is obtained by integrating the rainrate over time.

There has been some reluctance to use ORGs, perhaps because, unlike the volumetric funnel gauge, they are not readily calibrated by the user. At this stage, to exploit the advantages of both instruments, it seems good practice to mount a funnel gauge and ORG together high on the foremast (alongside the other meteorological sensors), where updraft due to the bulk of the ship is least, and the relative wind speed is available for any correction schemes deemed appropriate. Yuter and Parker (2001) review the performance of several type of rain gauges deployed close to each other during one cruise.

Figure 7 shows the rainfall time series obtained from several raingauges aboard NOAA's Ronald H. Brown during a cruise in the eastern Pacific (Hare et al., 2002). Wind corrections were applied with reasonable success, and poorly located siphon gauges were ignored. It illustrates the highly variable nature of rainfall, and the inherent difficulty in extrapolating space or time averages from observations at a single location. Their value lies in the potential for combining this accurate in situ record with spatial maps produced by remote sensing techniques, satellite-borne radiometers or shipboard C-band radars. The latter are capable of providing very detailed maps of rainfall intensity out to distances beyond $100 \mathrm{~km}$.

Because of the problems with conventional raingauges, there has been considerable effort to develop a disdrometer suitable for use at sea. The traditional disdrometer is an acoustic device designed to measure the rainfall drop size distribution (DSD). The raindrops impact on a diaphragm producing a sound signal which is a function of the drop diameter. Adding the discrete events produces the total rainfall. Attempts to use acoustic disdrometers on ships have not been very successful. Recently optical techniques have been used to obtain the DSD, and in this respect have much in common with optical raingauges. Employing yet another principal, a "hotplate" precipitation sensor has recently made its appearance. This consists of a heated circular metal plate, and obtains the rain rate from the amount of power needed to evaporate precipitation (or snow) falling on the plate, to keep its temperature constant. Although designed for land applications, it would seem to be suitable for shipboard, although the measurement range of the current model falls well short of tropical rain rates. One other technique which has shown considerable promise in measuring rainfall at sea, records the sound produced by rainfall impacting on the surface of the water (Nystuen et al., 2000). This very characteristic signal is recognized by an instrument attached to a mooring at a suitable depth (20-100 m).

\section{Sea-spray aerosol fluxes}

\subsection{Introduction}

Aerosol produced from the evaporation of sea-spray droplets make up the second largest source of aerosol mass injected into the atmosphere. Droplets are produced as film and jet drops from bursting bubbles - created by entrainment of air into the upper ocean by breaking waves - and from spume: drops of water ripped from wave crests by high winds. Measurement of aerosol fluxes differs significantly from that of other scalar quantities in that the aerosol particles of interest span a range of sizes of about 5 or 6 orders of magnitude. The flux of particles changes significantly with size; the flux must thus be measured at distinct, well-resolved, sizes. No single instrument can measure the full aerosol size spectrum. As particle radius increases from $0.01 \mu \mathrm{m}$ to $10 \mu \mathrm{m}$ the number concentration of particles decreases from around $10^{3}$ to $10^{0} \mathrm{ml}^{-1}$. Low concentrations at the largest sizes result in poor sampling statistics. A complicating factor is that 
sea-spray aerosol are hygroscopic, changing size rapidly in response to changes in ambient humidity; thus the sample humidity must also be measured and appropriate corrections applied to the flux.

Most existing estimates of the sea-spray source function have used indirect methods to infer the flux (for a comprehensive review see Lewis and Schwartz, 2004). Only a handful of studies have attempted direct eddy correlation measurement of the sea-spray aerosol flux. Nilsson et al. (2001) provided the first eddy correlation measurements of total number flux. Geever et al. (2005), De Leeuw et al. (2007), Norris et al. (2008) and Nilsson et al. (2007) have produced direct flux estimates with increasingly sophisticated levels of size segregation.

\subsection{Instruments}

Aerosol instrumentation has traditionally focussed on measuring mean properties of the particle distribution with averaging times of at least minutes. With a few exceptions the instruments are typically not weather proof; are bulky, making them difficult to site on masts or where space and weight are an issue; have a high power consumption, making remote battery-powered operation difficult or impossible; and are expensive enough that operation in environments where damage is likely may be an unacceptable risk.

Two classes of instrument are of interest for direct eddy correlation measurements of aerosol: condensation particle counters (CPCs) and optical particle counters (OPCs). The former draws the sample into an environment saturated with a readily condensable vapour - typically butanol, although water-based CPCs are increasingly available - the aerosol act as condensation nuclei and rapidly grow to form droplets that are detected optically via scattering of light. CPCs count the total number of particles within a broad size range, and do not provide any direct size information. The lower size limit is determined by the time available for droplets to grow and the sensitivity of the optical detection system, the upper size limit is effectively determined by the fluid dynamics through the incoming sample line with an increasing fraction of particles being lost with increasing size. The sampling rate of many CPCs is sufficient for eddy correlation measurements ( $\sim 3 \mathrm{~Hz}$ or greater), however the necessity of drawing the sample through an inlet tube, potentially many metres long, introduces a time lag and fine-scale variability in the atmospheric aerosol concentration may be lost due to mixing in the sample line. Although no direct size information is available, good eddy correlation estimates of the total flux within the CPC's measurement range can be obtained. Nilsson et al. (2001) made the first such measurements of sea-spray fluxes for particles with diameter $\mathrm{D}>10 \mathrm{~nm}$.

OPCs use the intensity of scattered laser light from aerosol to provide size information and thus produce a size-resolved concentration spectrum. Any given instrument can typically detect particles over a size range spanning one or two orders of magnitude. Geever et al. (2005) combined data from a CPC $(10 \mathrm{~nm}<\mathrm{D}<1 \mu \mathrm{m})$ with the aggregated counts from a Particle Measurement Systems (PMS) ASASP-X optical particle counter $(0.1<\mathrm{D}<1 \mu \mathrm{m})$ to make the first eddy correlation estimates of pseudo size segregated fluxes $(D>10 \mathrm{~nm}$, and $\mathrm{D}>100 \mathrm{~nm}$ ) at a coastal site. More recently the same instrumentation has been utilized to provide fully size segregated fluxes $(0.1<\mathrm{D}<2.5 \mu \mathrm{m})$ (Nilsson et al., 2007). The sample rate of the ASASP-X is only $1 \mathrm{~Hz}$, resulting in an estimated $25 \%$ underestimate in the magnitude of the measured fluxes. The sample line to the instrument results in a further underestimate increasing with size due to loss of particles to the walls, peaking at about $70 \%$ losses for the largest sizes.

In order to overcome some of the limitations of existing OPCs, a new instrument has been developed specifically for use in eddy correlation measurements: the Compact Lightweight Aerosol Spectrometer Probe (CLASP) (Hill et al., 2008). Based around a commercially available scatter cell, CLASP produces a 16-channel size spectrum at $10 \mathrm{~Hz}$ for particle sizes $0.24<\mathrm{D}<18.5 \mu \mathrm{m}$. A high sample flow of $50 \mathrm{ml} \mathrm{s}^{-1}$ improves the counting statistics by a factor of about 25 over the ASASP-X. The current version of CLASP measures just $25 \times 8 \times 6 \mathrm{~cm}$, and is thus readily collocated with a sonic anemometer eliminating the need for a long inlet tube and greatly reducing particle losses. The power consumption is of the order of $5 \mathrm{~W}$, allowing its use on powerlimited platforms such as buoys. The current version has been successfully run for periods of several weeks on research ships and for shorter periods on an autonomous buoy. The relatively low cost of CLASP allows multiple units to be deployed, and its use in locations where damage is likely: Fig. 9 shows two CLASP units deployed on a tethered buoy to make measurements within $1 \mathrm{~m}$ of the sea surface.

A distinction must be made between sea-spray aerosol and sea-salt aerosol, the latter being a distinct fraction of the former. There is considerable interest in partitioning the seaspray aerosol flux into its chemical constituents. This has been attempted at a bulk level via volatility techniques (de Leeuw et al., 2007; Nilsson et al., 2007) - the sample flow is heated to $300^{\circ} \mathrm{C}$ prior to entering an $\mathrm{OPC}$, this causes volatile components of the aerosol to vaporize leaving only non-volatile component to be sized; this is predominantly sea-salt for unpolluted marine aerosol. Simultaneous measurement of fluxes at ambient temperature allows the sea-salt fraction of the total flux to be estimated. In principal the technique could be extended with multiple systems operating at different temperatures characteristic of particular chemical compounds in order to provide a more complete breakdown of the bulk chemistry.

Eddy correlation measurement of sea-spray aerosol fluxes remains a technique in its infancy; much work remains to be done to establish robust techniques to handle the complexities of measuring size-resolved (and chemically resolved) particle fluxes. A particular problem is that the range of sizes 


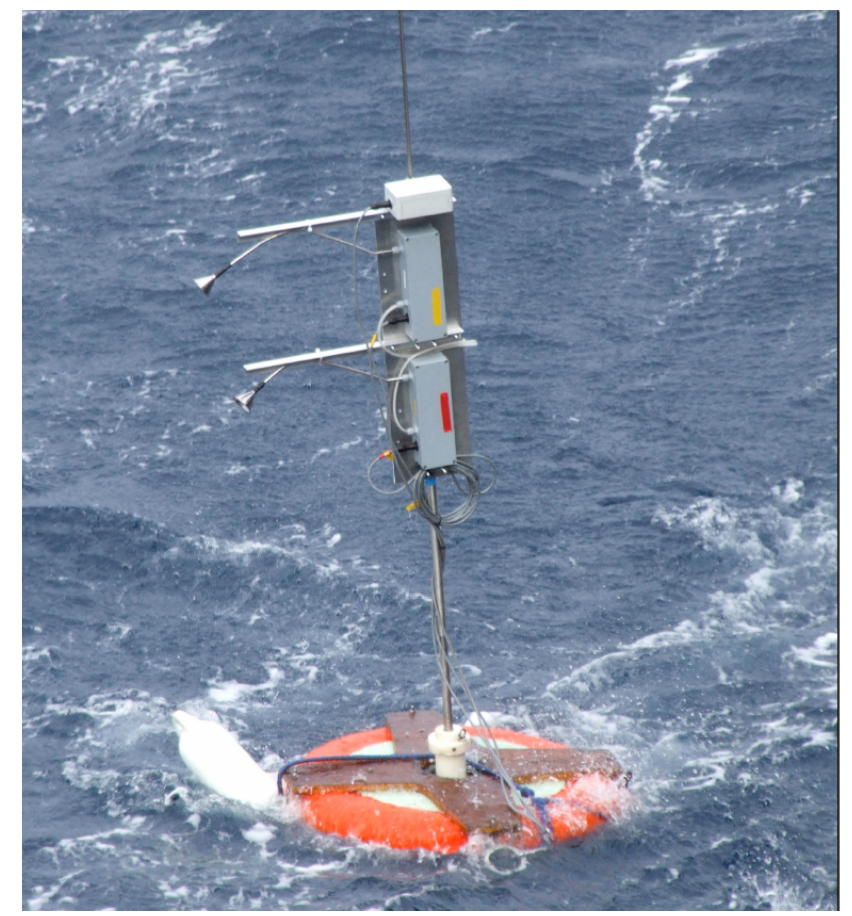

Fig. 9. Two CLASP units mounted on a tethered buoy sampling at approximately $0.6 \mathrm{~m}$ and $1 \mathrm{~m}$ above the ocean surface.

over which detailed size-resolved fluxes can be measured is rather narrow and must be extended in order to obtain a complete picture of sea-spray fluxes.

Another approach to measure aerosols at sea has been to field samplers on buoys that collect aerosols on filter paper (Sholkovitz and Sedwick, 2006). Air is sucked in, and a series of filter paper collectors are used to obtain aerosol sample time series.

\section{Summary}

In recent years significant progress has been made with the development of sensors and methodology for the measurement, from ship and buoy platforms, of air-sea fluxes of energy, heat, water, and salt. Bulk aerodynamic, inertial dissipation and eddy-correlation methods have been greatly improved, although work is still needed to extend the capabilities of all methods into the low and high wind regimes. Progress in the mid-range of conditions (wind speeds $\sim 3$ to $25 \mathrm{~m} \mathrm{~s}^{-1}$ ) can be gauged by the success of buoy and shipboard systems that are achieving accuracies of $10 \mathrm{~W} \mathrm{~m}^{-2}$ in daily and longer averages of net heat flux (Weller et al., 2004; Colbo and Weller, 2008). Even in these conditions we are constantly reminded of the critical importance of devoting adequate time to pre-deployment calibration of sensors in the lab and on land, and for intercomparison and field validation of accuracy at sea (e.g., by positioning a well-equipped

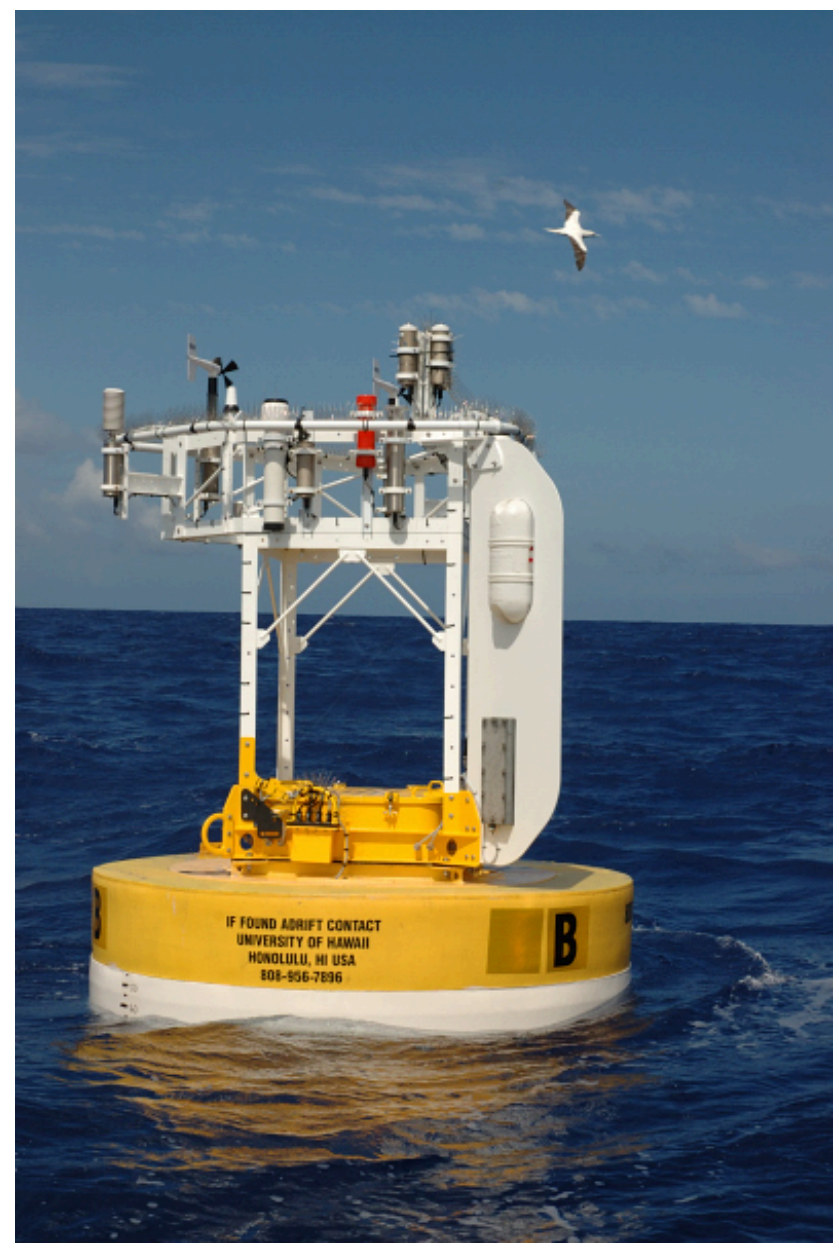

Fig. 10. Surface buoy, showing wind-orienting vane to keep sensors on the upwind face, wide separation of sensors, and placement of radiometers as high as possible.

ship, bow into the wind and just downwind of a surface buoy instrumented for fluxes, both just after deployment and just before recovery). Careful location of sensors, avoiding shadows, flow disturbance, and heat island effects remains essential (Fig. 10).

Nevertheless, there is a continuing need to investigate the performance of some existing sensors (e.g. calibration and comparability of radiometers remains a challenge) and to introduce and develop new sensors, for wave measurement for example. Continuing development of practical ways to apply routinely the results of computer modeling of wind flow distortion around instrument platforms is necessary. Efforts to increase the amount of power available on buoys will be crucial for future long-term deployments. This will allow aspiration of air temperature and humidity sensors, and of radiometer bodies, to reduce errors due to solar heating. It will also allow the installation of turbulent flux sensors simultaneously with the present bulk aerodynamic meteorological systems, and perhaps also active leveling of radiometer mounts. 
Greater power availability will also allow use of heaters and de-icers; until such facilities are possible, coping with ice and freezing sea spray remains a significant challenge. Also essential is ongoing work to extend capabilities to extreme wind conditions. The measurement of aerosol fluxes and the coincident measurement of chemical and physical fluxes are important pathways for the future as the need to understand the role of the ocean in climate becomes increasingly critical.

Long term deployments of surface buoys are now delivering sustained climate-quality surface flux observations from ocean sites. Global co-ordination of these sites is continuing through international efforts such as OceanSITES (www.oceansites.org). Many of the above technical improvements on observing platforms are progressing, including the development of surface buoys for long-term deployment at high latitude sites. The need for such in-situ meteorological and flux observations is critical for many applications. They are required to ground-truth and validate remotely sensed observations, and to initiate and verify atmospheric and coupled ocean-atmosphere models. In-situ data from these moorings and other sources is also being used to compare and improve air-sea fluxes derived from remotely sensed surface meteorological variables (e.g., http://seaflux.gfdi.fsu.edu). They also provide anchor sites for development of air-sea flux fields and climatologies that optimally blend diverse data sets (e.g. Yu and Weller, 2007).

Acknowledgements. The authors thank their many colleagues in the endeavour of making improved observations of air-sea fluxes and surface meteorology over the ocean for their contributions and, as a result, for their assistance with this paper. The comments of Tommy Dickey and the editor are greatly appreciated. The lead author acknowledges support of the NOAA Climate Observation Program.

Edited by: G. Griffiths

\section{Appendix A}

\section{Useful links}

- http://www.eppleylab.com/ manufacturer of shortwave and longwave sensors

- http://www.kippzonen.com/ manufacturer of meteorological sensors

- http://www.groddeck-defense.de/devices/sensgaug.htm Eigenbrodt precipitation sensors and rain gauges

- http://www.whoi.edu/instruments/viewInstrument. do?id=12827 Woods Hole Oceanographic Institution overview of ASIMET (Air-Sea Interaction METeorological system for ships and buoys)
- http://www.soc.soton.ac.uk/JRD/MET/AUTOFLUX/ DOCS/Weller.Taylor.98/Weller.taylor.html reference on shipboard, buoy systems

- http://www.youngusa.com/ RM Young company website, maker of meteorological instruments

- http://www.rotronic-usa.com/ Rotronic, maker of humidty sensors and instruments

- http://www.vaisala.com/ Weather instruments and sensors

- http://www.gill.co.uk/index.htm Gill home page, makers of sonic anemometers

- http://www.kaijosonic.co.jp/index\{_\}e.html Kaijo Sonic Corp. , maker of sonic anemometers

- http://www.licor.com/env/ Licor, maker of infrared hygrometer

- http://www.coastalenvironmental.com/content/ aboutcoastal.html commerical manufacturer of weather buoys

- http://www.aadi.no/Aanderaa/Products/AWS/default. aspx commercial manufacturer of weather systems, buoys

- http://www.oceanor.no/products/seawatch\{\%\} 20buoys $\{\%\} 20$ sensors.htm Fugro-Oceanor, commercial manufacturer of buoys

- http://www.yesinc.com/ manufacturer of meteorological sensors

- http://www.opticalscientific.com/ manufacturer of meteorological sensors

\section{References}

Anderson, S. P. and Baumgartner, M. F.: Radiative heating errors in naturally ventilated air temperature measurements made from buoys, J. Atmos. Oceanic. Tech., 15, 157-173, 1998.

Barton, I. J., Minnett, P. J., Maillet, K. A., Donlon, C. J., Hook, S. J., Jessup, A. T., and Nightingale, T. J.: The Miami2001 infrared radiometer calibration and intercomparison, Part II: shipboard results. J. Atmos. Ocean. Tech., 21, 268-283, 2004.

Bradley, E. F. and Fairall, C. W.: A guide to making climate quality meteorological and flux measurements at sea, NOAA Technical Memorandum OAR PSD-311, Earth System Research Laboratory, Boulder, CO, 2007.

Brown, E. N., Friehe C. A., and Lenschow, D. H.: The use of pressure fluctuations on the nose of an aircraft for measuring air motion, J. Climate Appl. Meteor., 22, 171-180, 1983.

Crawford, T. L. and Dobosy, R. J.: A sensitive fast-response probe to measure turbulence and heat flux from any airplane, Bound.Layer Meteor., 59, 257-278, 1992. 
Colbo, K. and Weller, R. A.: The accuracy of the IMET sensor package in the subtropics, J. Atmos. Ocanic. Tech., in review, 2008.

de Leeuw, G., Moerman, M. M., Zappa, C. J., McGillis, W. R., Norris, S. J. and Smith, M. H.: Eddy Correlation Measurements of Sea Spray Aerosol Fluxes, in: Transport at the Air Sea Interface, edited by: Garbe, C. S., Handler, R. A. and Jähne, B., SpringerVerlag Berlin, Heidelberg, 2007.

Dickey, T., Manov, D., Weller, R., and Siegel, D.: Determination of longwave net heat flux at the air-sea interface using measurements from buoy platforms, J. Atmos. Ocean. Tech., 1, 10571078, 1994.

Donlon, C. J., Minnett, P. J., Gentemann, C., Nightingale, T. J., Barton, I. J., Ward, B., and Murray, M. J.: Towards improved validation of satellite sea surface skin temperature measurements for climate research, J. Climate, 15, 353-369, 2002.

Drennan, W. M., Taylor, P. K., and Yelland, M. J.: Parameterizing the sea surface roughness, J. Phys. Oceanogr., 35, 835-848, 2005.

Dupuis, H., Guerin, C., Hauser, D., Weill, A., Nacass, P., Drennan, W. M., Cloche, S., and Graber, H. C.: Impact of flow distortion corrections on turbulent fluxes estimated by the inertial dissipation method during the FETCH experiment on R/V L'Atalante, J. Geophys. Res., 108, 8064, doi:10.1029/2001JC001075, 2003.

Eckman, R. M., Dobosy, R. J., Auble, D. L., Strong, T. W., and Crawford, T. L.: A pressure-sphere anemometer for measuring turbulence and fluxes in hurricanes, J. Atmos. Oceanic. Tech., 24, 994-1007, 2007.

Edson, J. B., Fairall, C. W., Larsen, S. E., and Mestayer, P. G.: A study of the inertial-dissipation technique for computing airsea fluxes, J. Geophys. Res., 96, 10 689-10711, 1991.

Edson, J. B. and Fairall, C. W.: Similarity relationships in the marine atmospheric surface layer for terms in the TKE and scalar variance budgets. J. Atmos. Sci., 55, 2311-2328, 1998.

Edson, J. B., Hinton, A. A., Prada, K. E., Hare, J. E., and Fairall, C. W.: Direct covariance flux estimates from mobile platforms at sea, J. Atmos. Oceanic. Tech., 15, 547-562, 1998.

Edson, J. B.: Sensors for micrometeorological flux measurements, in: Encyclopedia of Ocean Sciences, vol. 5, edited by: Steele, J., Thorpe, S., and Turekian, K., Academic Press, London, pp. 2751-2759, 2001.

Emanuel, K. A.: Sensitivity of tropical cyclones to surface exchange coefficients and a revised steady-state model incorporating eye dynamics, J. Atmos. Sci., 52, 3969-3976, 1995.

Fairall, C. W. and Larsen, S. E.: Inertial-dissipation methods and turbulent fluxes at the air-ocean interface, Boundary-Layer Meteor., 34, 287-301, 1986.

Fairall, C. W., Bradley, E. F., Godfrey, J. S., Wick, G. A., Edson, J. B., and Young, G. S.: The cool skin and the warm layer in bulk flux calculations, J. Geophys. Res., 101, 1295-1308, 1996a.

Fairall, C. W., Bradley, E. F., Rogers, D. P., Edson, J. B., and Young, G. S.: Bulk parameterization of air-sea fluxes for TOGA COARE, J. Geophys. Res., 101, 3747-3764, 1996b.

Fairall, C. W., White, A. B., Edson, J. B., and Hare, J. E.: Integrated shipboard measurements of the marine boundary layer, J. Atmos. Oceanic Tech., 14, 338-359, 1997.

Fairall, C. W., Persson, P. O. G., Bradley, E. F., Payne, R. E., and Anderson, S.: A new look at calibration and use of Eppley Precision Infrared Radiometers, Part I: Theory and application, J.
Atmos. Oceanic Tech., 15, 1229-1242, 1998.

Fairall, C. W., Bradley, E. F., Hare, J. E., Grachev, A. A., and Edson, J. B.: Bulk parameterization of air-sea fluxes: Updates and verification of the COARE algorithm, J. Climate, 16, 571-591, 2003.

Frederikson, P. A., Davidson, K. L., and Edson, J. B.: A study of wind stress determination methods from a ship and offshore tower, J. Atmos. Oceanic. Tech., 14, 822-834, 1997.

Frolilich, C.: History of radiometry and the World Radiometric Reference, Metrologia, 28, 111-115, 1991.

Geever, M. C., O’Dowd, D., van Ekeren, S., Flanagan, R., Nilsson, E. D., de Leeuw, G., and Rannik, Ü.: Submicron sea spray fluxes, Geophys. Res. Lett., 32, L15810, doi:10.1029/2005GL023081, 2005 .

Gosnell, R., Webster, P. J., and Fairall, C. W.: The sensible heat flux due to rain in TOGA COARE, J. Geophys. Res., 100, 18437 $18442,1995$.

Hare, J., Bradley, E. F., and Fairall, C. W.: Rainfall measurements on the R/V Ronald H. Brown during EPIC2001, Proc. AGU Fall Meeting, San Francisco, CA, USA, 2002.

Hasse, L., Grossklaus, M., Uhlig, K., and Timm, P.: A ship rain gauge for use in high winds. J. Atmos. Oceanic. Tech., 15, 380386, 1998 .

Hill, M. K., Brooks, B. J., Norris, S. J., Smith, M. H., Brooks, I. M., and de Leeuw, G.: Compact Lightweight Aerosol Spectrometer Probe (CLASP), J. Atmos. Oceanic. Tech., 25,(11), 1996-2006, 2008.

Janssen, P. A. E. M.: On the effect of ocean waves on the kinetic energy balance and consequences for the inertial dissipation technique, J. Phys. Oceanogr., 29, 530-534, 1999.

Ji, Q. and Tsay, S.-C.: On the dome effect of Eppley pyrgeometers and pyranometers, Geophys. Res. Lett., 27, 971-974, 2000.

Lange, B., Johnson, H. K., Larsen, S., Hojstrup, J., Kofoed-Hansen H., and Yelland, M. J.: On detection of a wave age dependency for the sea surface roughness, J. Phys. Oceanog., 34, 1441-1458, 2004.

Large, W. G., Morzel, J., and Crawford, G. B.: Accounting for surface wave distortion of the marine wind profile in low-level ocean storm wind measurements, J. Phys. Oceanogr., 25, 2959-2971, 1995.

Large, W. G. and Pond, S.: Open ocean momentum flux measurements in moderate to strong winds, J. Phys. Oceanogr., 11, 324336, 1981.

Larsen, S. E., Edson, J. B., Fairall, C. W., and Mestayer, P. G.: Measurement of temperature spectra by a sonic anemometer, J. Atmos. Oceanic Tech., 10, 345-354, 1993.

Lewis, E. R. and Schwartz, S. E.: Sea Salt Aerosol Production Mechanisms, Methods, Measurements, and Models, American Geophysical Union, 413 pp., 2004.

Miller, M. J., Beljaars, A. C. M., and Palmer, T. M.: The sensitivity of the ECMWF model to the parameterization of evaporation from the tropical oceans, J. Climate, 5, 418-434, 1992.

Moat, B. I., Yelland, M. J., Pascal, R. W., and Molland, A. F.: An overview of the airflow distortion at anemometer sites on ships, Int. J. Climatol., 25, 997-1006, 2005

Nilsson, E. D., Rannik, Ü., Swietlicki, E., Leck, C., Aalto, P. P., Zhou, J., and Norman, M.: Turbulent aerosol fluxes over the Arctic Ocean: 2. Wind driven sources from the sea, J. Geophys. Res., 106, 32 139-32 154, 2001. 
Nilsson, E. D., Mårtensson, E. M., van Ekeren, J. J., de Leeuw, G., Moerman, M., and O'Dowd, C. D.: Primary marine aerosol emissions: size resolved eddy covariance measurements of the sea salt and organic carbon fractions, Atmos. Chem. Phys. Discuss., 7, 13 345-13 400, 2007,

http://www.atmos-chem-phys-discuss.net/7/13345/2007/.

Norris, S. J., Brooks, I. M., de Leeuw, G., Smith, M. H., Moerman, M., and Lingard, J. J. N.: Eddy covariance measurements of sea spray particles over the Atlantic Ocean, Atmos. Chem. Phys., 8, 555-563, 2008, http://www.atmos-chem-phys.net/8/555/2008/.

Nystuen, J. A., McPhaden, M. J., and Freitag, H. P.: Surface measurements of precipitation from an ocean mooring: The underwater acoustic log from the South China Sea, J. Appl. Meteor., 39, 2182-2197, 2000.

Ohlman, J. C., Siegel, D. A., and Mobley, C. D.: Ocean radiant heating. Part I: Optical influences, J. Phys. Oceanogr., 30, 18331848, 2000.

Ohlman, J. C. and Siegel, D. A.: Ocean radiant heating. Part II: Parameterizing solar radiation transmission through the upper ocean, J. Phys. Oceanogr., 30, 1849-1865, 2000.

Oost, W. A. E., Worrell, W. H., Schaap, J. W., van Oort, C., and Kraan, C.: An improved version of the pressure anemometer, J. Atmos. Oceanic. Tech., 8, 575-584, 1991.

Pascal, R. W. and Josey, S. A.: Accurate Radiometric Measurement of the Atmospheric Longwave Flux at the Sea Surface, J. Atmos. Oceanic Technol., 17, 1271-1282, 2000.

Payne, R. E.: Albedo of the sea surface, J. Atmos. Sci., 29, 959970, 1972.

Payne, R. E. and Anderson, S. P.: A new look at calibration and use of Eppley Precision Infrared Radiometers. Part II. Calibration and use of the Woods Hole Oceanographic Institution Improved Meteorology Precision Infrared Radiometer, J. Atmos. Oceanic Tech., 16, 739-751, 1999.

Popinet, S., Smith, M., and Stevens, C.: Experimental and numerical study of the turbulence characteristics of airflow around a research vessel, J. Atmos. Oceanic Technol., 21, 1575-1589, 2004.

Rediniotis, O. K. and Kisner, R. E.: Development of a nearly omnidirectional velocity measurement pressure probe, AIAA J., 36, 1854-1860, 1998.

Richardson, S. J., Brock, F. V., Semmer, S. R., and Jirak, C.: Minimizing errors associated with multiplate radiation shields, J. Atmos. Oceanic Tech., 16, 1862-1872, 1999.

Schmitt, K. F., Friehe, C. A., and Gibson, C. H.: Humidity sensitivity of atmospheric temperature sensors to salt contamination, J. Phys. Oceanogr., 8, 151-161, 1978.

Schotanus, P., Nieuwstadt, F. T. M., and de Bruin, H. A. R.: Temperature measurement with a sonic anemometer and its application to heat and moisture fluxes, Bound.-Layer Meteor., 26, 81-93, 1983.

Shakespeare, W.: Hamlet, Prince of Denmarke, act I, scene IV, line $18,1603$.

Smith, S. D.: Wind Stress and Heat Flux over the Ocean in Gale Force Winds, J. Phys. Oceanogr., 10, 709-726, 1980.
Soloviev, A. and Lukas, R.: The Near-Surface Layer of the Ocean, Springer, Dordrecht, The Netherlands, 572 pp., 2006.

Takahashi, S., Kondo, F., Tsukamoto, O., Ito, Y., Hirayama, S., and Ishida, H.: On-board automated eddy flux measurement system over open ocean, SOLA, 1, 37-40, doi:10.2151/sola.2005-011, 2005.

Taylor, P. K., Dunlap, E., Dobson, F. W., Anderson, R. J., and Swail V. R.: On the accuracy of wind and wave measurements from buoys, Data Buoy Cooperation Panel Tech. Doc. No. 21-2002, Presentations at the DBCP Technical Workshop, Perth, Australia, October, 2001.

Taylor, P. K. and Yelland, M. J.: On the apparent "imbalance" term in the turbulent kinetic energy budget, J. Atmos. Oceanic Tech., 17, 82-89, 2000.

Taylor, P. K. and Yelland, M. J.: Comments on "On the effect of ocean waves on the kinetic energy balance and consequences for the inertial dissipation technique". J. Phys. Oceanog., 31, 25322536, 2001.

Thomas, B. R., Kent, E. C., and Swail, V. R.: Methods to homogenize wind speeds frrom ships and buoys, Int. J. Climatol., 25, 979-995, 2005.

WCRP: World Climate Research Programme, Final report of the Joint WCRP/SCOR Working Group on Air-Sea Fluxes (SCOR Working Group 110): Intercomparison and Validation of OceanAtmosphere Energy Flux Fields. WCRP-112, WMO/TD-No. 1036, Case Postale No. 2300, CH-1211 Geneva 2, Switzerland, 362 pp., 2000.

Weller, R. A. and P. K. Taylor: Surface conditions and air-sea fluxes. OOSDP Background Report \#3. CCCO-JSC Ocean Observing System Development Panel, Texas A\&M University, College Station, Texas, USA, 131 pp., 1993.

Weller, R. A., Bradley, E. F., and Lukas, R.: The interface or airsea flux component of the TOGA Coupled Ocean-Atmosphere Response Experiment and its impact on subsequent air-sea interaction studies, J. Atmos. Oceanic Tech., 21, 223-257, 2004.

Yelland, M. J., Taylor, P. K., Consterdine, I. E., and Smith, M. H.: Use of the inertial dissipation technique for shipboard wind stress determination, J. Atmos. Oceanic. Tech., 11, 1093-1108, 1994.

Yelland, M. J., Moat, B. I., Taylor, P. K., Pascal, R. W., Hutchings, J., and Cornell, V. C.: Wind stress measurements from the open ocean corrected for air flow distortion by the ship, J. Phys. Oceanogr., 28, 1511-1526, 1998.

Yelland, M. J., Moat, B. I., Pascal, R. W., and Berry, D. I.: CFD model estimates of the airflow distortion over research ships and the impact on momentum flux measurements, J. Atmos. Oceanic Tech., 19, 1477-1499, 2002.

Yu, L. and Weller, R. A.: Objectively analyzed air-sea heat fluxes for the global ice-free oceans, Bull, Amer. Meteor. Soc., 88, 527539, 2007.

Yuter, S. E. and Parker, W. S.: Rainfall measurement on ship revisited: The 1997 PACS TEPPS cruise, J. Appl. Meteorol., 40, 1003-1018, 2001. 